\title{
Hemingway's Internal Deviation from His Primary Norm in The Old Man and the Sea
}

\author{
Trisnowati Tanto \\ English Department, Faculty of Letters, Maranatha Christian University, Surya \\ Sumantri 65, Bandung 40164, West Java, Indonesia \\ e-mail: trisnowati@yahoo.com
}

\begin{abstract}
Ernest Hemingway is well known for the use of short and simple sentences when writing his novels since he aims at '[getting] the most out of the least'. This sentence-simplicity style is Hemingway's primary norm. The Old Man and the Sea is the perfect example of this. However, in this novel, he sometimes uses long, complex sentences to describe certain points, and this sentence-complexity style can be said to be Hemingway's secondary norm. In this case, there is a deviation within Hemingway's own style of writing - an internal deviation. The deviation is obviously done on purpose as a kind of distraction so as to make the readers aware of the special and important 'message' that Hemingway wants to convey. In this novel, the deviation is used to build the elements of suspense and foreshadowing in much detail.
\end{abstract}

Key words: style of writing, primary norm, secondary norm, internal deviation, distraction, suspense, foreshadowing

The study of an author's style of writing belongs to stylistics and according to Wales (1994)

in many respects, ..., stylistics is close to literary criticism and PRACTICAL CRITICISM. By far the most common kind of material studied is LITERARY, and attention is largely TEXT-centred. .... The goal of most stylistic studies is not simply to describe the formal features of texts for their own sake, but in order to show their FUNCTIONAL significance for the INTERPRETATION of the text; or in order to relate literary effects to linguistic 'causes' where these are felt important to be relevant (pp. 437-438).

Furthermore, Wales states that we need intuition and interpretive skills in stylistics. However, “... to avoid vague and impressionistic judgments 
about the way formal features are manipulated, ... stylistics draws on the models and terminology provided by whatever aspects of linguistics are felt to be relevant” (p. 438).

In studying style, which at its simplest refers to "... the manner of expression in writing or speaking” (p. 435), we may relate it to particular authors. In this respect, style can be defined as "...the choice of items, and their distribution and patterning” (p. 436).

Some authors are known to have the style of writing which makes them special and distinctive from any other author. Ernest Hemingway, one of the American greatest novelists of 'The Lost Generation', is undoubtedly an author with a consistent use of writing style. His powerful, style-forming mastery of the art of narration, in fact, made him awarded the Noble Prize for Literature in 1954.

The Old Man and the Sea is his masterpiece and it gave him the Pulitzer Prize in 1952. It tells about Santiago, an old fisherman, who has not caught any fish for eighty-four days. On the eighty-fifth day, however, Santiago catches a giant marlin. When sailing back home, a group of sharks attack and eat the marlin and leave only its skeleton.

Hemingway is best known for the use of sentence-simplicity style of writing. He uses short and simple sentences which are relatively easier to understand. "The simple style and careful structuring of Hemingway's fiction is famous....The aim of his style was "to get the most out of the least” (High, 1986, p. 147).

Hemingway's sentences are usually short and simple. "Only rarely does he use adjectives ... the language is rarely emotional. Rather, it controls emotions; it holds them in" (p. 147).

\section{INTERNAL DEVIATION}

One approach to style is to compare one set of features with another in terms of a DEVIATION from a NORM. Of course, it does not mean that style itself is deviant in the sense of 'abnormal'. Rather, we match any text or piece of language against the linguistic norms of its genre, or its period, and the common core of the language as a whole (Wales, 1994, p. 437).

Internal deviation is generally presented in poetry, but it can also be found in a novel. "Internal deviation explains the prominence, not uncommon in prose fiction, of an ordinary, even banal piece of language which seems to gain its impact from the context in which it is found" 
(Leech and Short, 1994, p. 55). Internal deviation happens because there is a change in the language used and it is something different from what the readers have expected or believed before. 'Features of language within that text, which depart from the norm of the text itself: that is, they may 'stand out' against the background of what the text has led us to expect” (p. 55). In other words, internal deviation happens because there is a secondary norm in the text. "The norm which is 'attained' by stylistic consistency in a text might be called a SECONDARY NORM, since it is established by deviance from the PRIMARY (relative) NORM which determines our more general expectations of language” (p. 55). In this case, Ernest Hemingway's primary norm is sentence-simplicity style; yet, he intentionally uses a secondary norm, namely sentence-complexity style.

From the reference books that I have read so far, there are no clear definitions of simplicity and complexity styles of writing. Thus, in this article I think it is necessary to make some limitation of what are defined as simplicity and complexity styles of writing. Based on Leech and Short's opinion, sentence-simplicity style can be represented by three diagrams. Each box represents one simple sentence. A horizontal linking line as that in number 2 represents coordination, while an oblique line as that in number 3 represents subordination.

1.

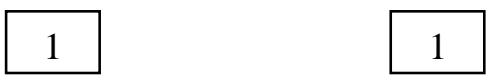

Example: Jim threw the ball. The ball broke a window.

\section{1}

The noise attracted the attention of the owner.

\section{1}

The owner scolded him.

2..

\begin{tabular}{|l|l|}
\hline 1 & 2 \\
\hline
\end{tabular}

Example: Jim threw the ball and broke the window.

3..

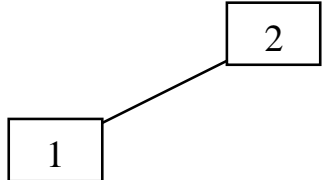

Example: When Jim threw the ball, he broke the window. 
Other than the three diagrams above, the sentence will be regarded as sentence-complexity style. One example of a sentence with a complexity style is as follows:

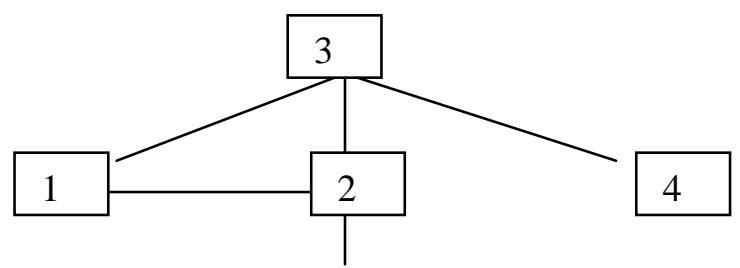

Example: When Jim threw the ball and broke the window, he was scolded by the owner, whose attention was attracted by the noise.

According to Crystal (1987, p. 94), a subject (the topic) plus a predicate (what is being said about the topic), which are begun by a capital letter and ended by a full stop, are enough to be called a sentence. But whether a sentence is called a simple or complex sentence, will be decided by its structure.

A simple sentence consists of one clause only (Leech and Short, 1994, p. 217). A simple sentence “... represents a naïve narrative style in which there is no indication of the relationship between events, or of their relative importance" (p.219). In other words, each clause stands on its own feet, and is considered to have the equal importance with the others. A writer may write his sentences in sentence-simplicity style and the effect on the readers is that they will experience the events one by one (p. 220).

"A complex sentence consists of more than one clause. In a complex sentence, the clauses are related to one another by subordination or by coordination” (p.217). According to Crystal (1987),

coordination is one of the two main ways of making sentences more complex. The other way is known as subordination, or 'embedding'. The essential difference is that in the former the clauses that are linked are of equal grammatical status, whereas in the latter, one clause functions as part of another (the main clause) (p.95).

Examples of coordinating conjunctions are and, but, or; and those of subordinating conjunctions are when, if, why, whether, because, since, etc. (Jackson, 1980, p. 65).

A complex sentence “... gives and withholds information, subordinates some ideas to others more important, coordinates those of 
equal weight, and ties into a neat package as many suggestions, modifiers, and asides as the mind can attend to in one stretch" (Leech and Short, 1994, p. 219).

The aim of the writer in using sentence-complexity style is to present the readers with a complex structure of ideas, so as to make the readers feel a complex reading experience. By reading sentences that have sentencecomplexity style, the readers will experience the events as an articulate and complex whole (pp. 219-220).

\section{FINDINGS AND DISCUSSION}

In the following part I present the analysis of Hemingway's sentences in The Old Man and the Sea which use sentence-complexity style which is used to support the literary aspects such as to support the plot, namely suspense and foreshadowing.

\section{Table 1. Data 1 of Sentence-Complexity Style to Support Foreshadowing:}

a Sentence of He was asleep in a short time and he dreamed of Complexity Africa when he was a boy and the long, golden Style beaches, and the white beaches, so white they hurt your eyes, and the high capes and the great brown mountains.

\begin{tabular}{ll}
\hline Form & dreaming of Africa with its beautiful beaches \\
Main Idea & He lived along that coast now every night and in \\
b Sentence of \\
Complexity \\
Style
\end{tabular}




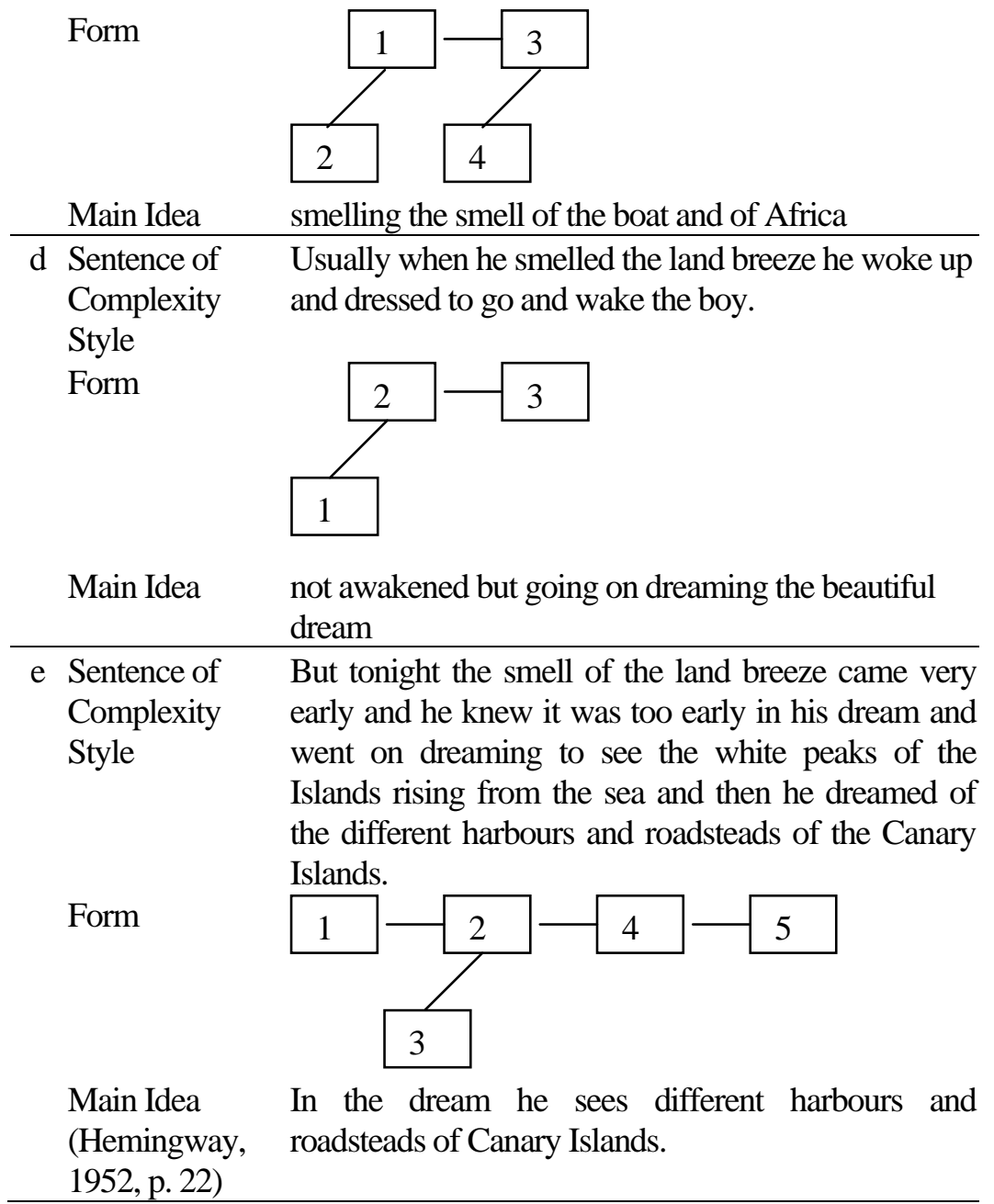

This part of the story refers to the old man's unusual dream. He dreams about something beautiful and it pleases him. He also dreams about the new harbours which the boats step on. This serves as a foreshadowing that something different and unusual will happen the next day, the day when he is determined to go to the sea to fish again, the day when something extraordinary will take place. 
Table 2. Data 2 of Sentence-Complexity Style to Support Suspense

$\begin{array}{ll}\begin{array}{l}\text { Sentence of } \\ \text { Complexity Style }\end{array} & \begin{array}{l}\text { 'Now!' he said aloud and struck hard with both } \\ \text { hands, gained a yard of line and then struck again } \\ \text { and again, swinging with each arm alternately on } \\ \text { the cord with all the strength of his arms and the } \\ \text { pivoted weight of his body. }\end{array} \\ \text { Form } & \begin{array}{l}\text { Screaming, striking hard, gaining a yard of line, } \\ \text { striking again and again, swinging with each arm } \\ \text { (p. 42) }\end{array}\end{array}$

Hemingway's idea here is to describe vividly the old man's great effort in trying to catch the big fish. All the verbs in this part, struck, gained, struck, swinging, are used to strengthen the writer's aim, namely to build the readers' suspense. He also makes the readers convinced and able to visualize that the old man's effort is really great, especially with the use of such adverbs as aloud, hard, again and again, alternately, with the strength of his arms and the pivoted weight of his body.

\section{Table 3. Data 3 of Sentence-Complexity Style to Support Suspense}

$\begin{aligned} & \text { Sentence of } \\ & \text { Complexity Style } \\ & \text { The clouds were building up now for the trade } \\ & \text { wind and he looked ahead and saw a flight of wild } \\ & \text { ducks etching themselves against the sky over the } \\ & \text { water, then blurring, then etching again and he } \\ & \text { knew no man was ever alone on the sea. }\end{aligned}$
$\begin{aligned} & \text { Form } \\ & \text { Main Idea } \\ & \text { (p. 57) }\end{aligned}$


In this part, the old man realizes that he is completely alone in the middle of the sea. He is just accompanied by the targeted fish and the ducks that he sees etching and blurring in the sky. This condition is clearly portrayed and this adds to the readers' suspense whether or not the old man is able to catch the fish and come back safe to the shore.

Table 4. Data 4 of Sentence-Complexity Style to Support Foreshadowing

a Sentence of He did not dream of the lions but instead of a Complexity Style vast school of porpoise that stretched for eight or ten miles and it was in the time of their mating and they would leap high into the air and return into the same hole they had made in the water when they leaped.

Form

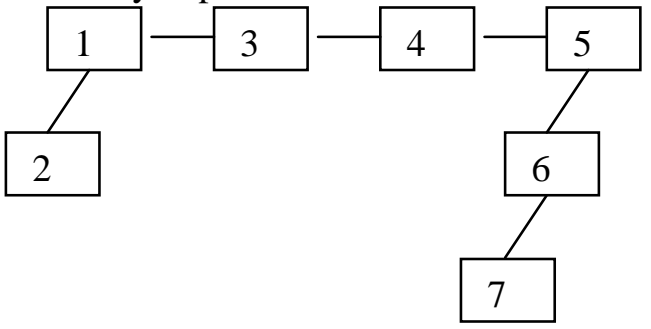

Main Idea dreaming of a vast school of porpoise which jump high into the air

b Sentence of Then he dreamed that he was in the village on Complexity Style his bed and there was a norther and he was very cold and his right arm was asleep because his head had rested on it instead of a pillow.

Form

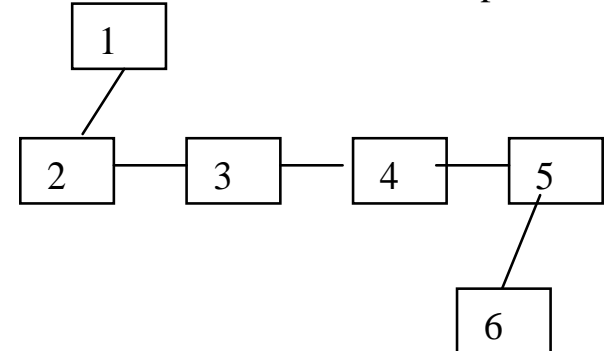

Main Idea dreaming of sleeping on his bed in the village 


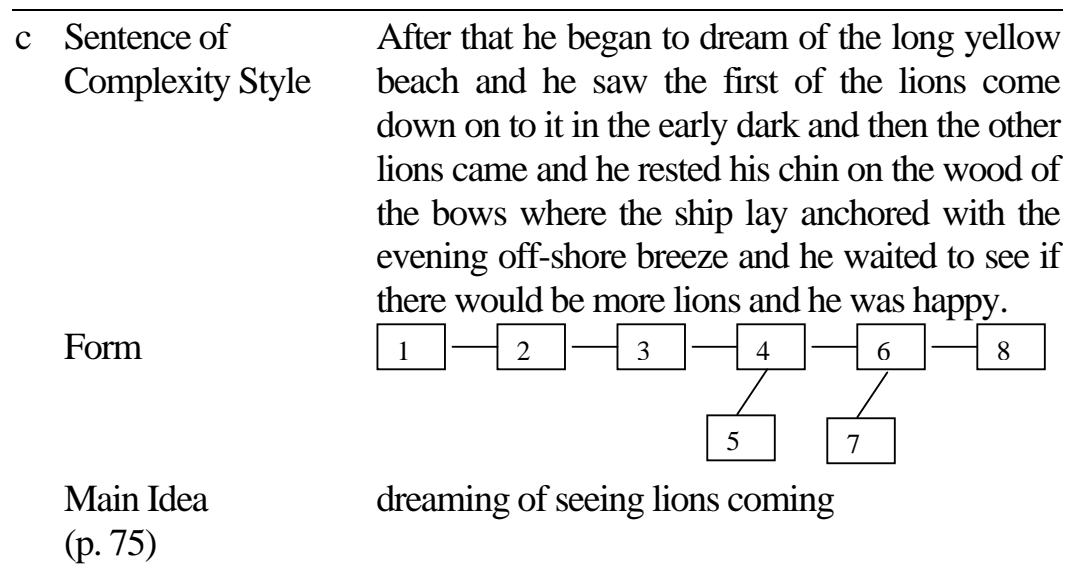

The old man usually dreams about lions. This time, however, he has the strange dream of seeing a vast school of porpoise first and then some lions at the end of his dream. With this strange and different dream, I am of the opinion that a different condition will happen to the old man, that is, he will get the fish. Therefore, this is a brilliant foreshadowing for the readers.

\section{Table 5. Data 5 of Sentence-Complexity Style to Support Suspense}

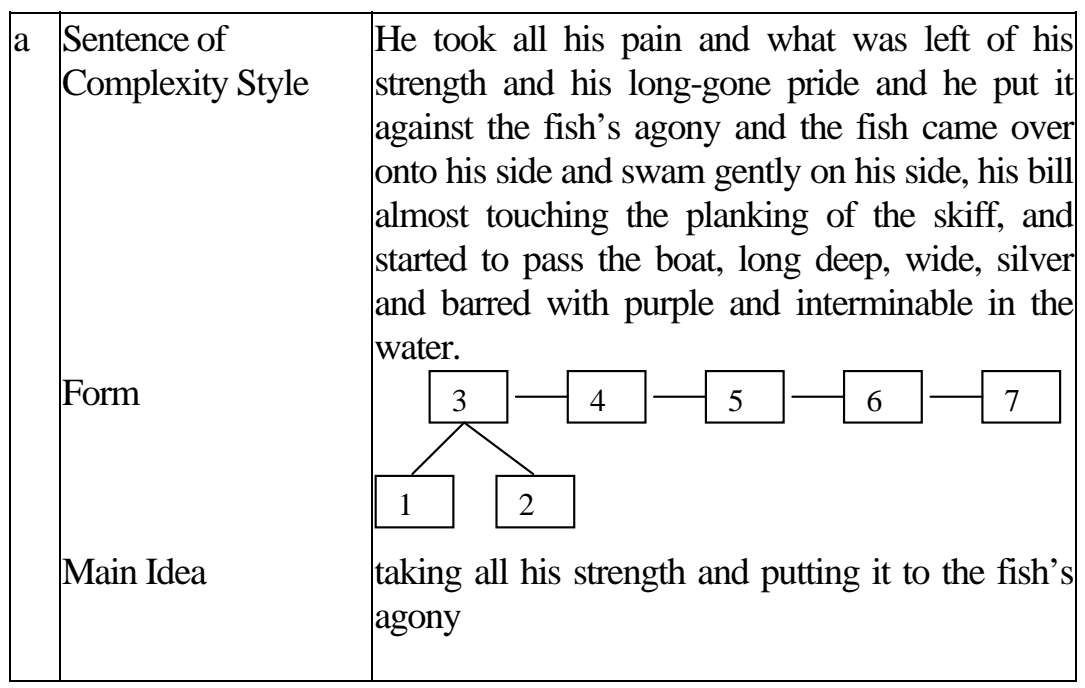




\begin{tabular}{|l|l|l|}
\hline $\mathrm{b}$ & $\begin{array}{l}\text { Sentence of } \\
\text { Complexity Style }\end{array}$ & $\begin{array}{l}\text { The old man dropped the line and put his foot on } \\
\text { it and lifted the harpoon as high as he could and } \\
\text { drove it down with all his strength he had just } \\
\text { summoned, into the fish's side just behind the } \\
\text { great chest fin that rose high in the air to the } \\
\text { altitude of the man's chest. }\end{array}$ \\
Form & $\begin{array}{l}\text { Main Idea } \\
\text { dropping the line, putting his foot on it, lifting the } \\
\text { harpoon, driving it down with all his strength }\end{array}$ \\
\hline $\begin{array}{l}\text { Sentence of } \\
\text { Complexity Style }\end{array}$ & $\begin{array}{l}\text { He felt the iron go in and he leaned on it and } \\
\text { drove it further and then pushed all his weight } \\
\text { after it. } \\
\text { Form }\end{array}$ & $\begin{array}{l}1 \\
\text { feeling the iron go in, leaning on it, driving it } \\
\text { further, pushing all his weight after it }\end{array}$ \\
\hline Main Idea \\
(pp. 85-87)
\end{tabular}

In these sentences, Hemingway describes the old man's battle with the fish. The readers are made to feel the suspense and also to realize that the old man's struggle is as long and complex as shown by the use of the complex sentences above.

\section{Table 6. Data 6 of Sentence-Complexity Style to Support Suspense}

a Sentence of

They were hateful sharks, bad-smelling, Complexity Style scavengers as well as killers, and when they were hungry they would bite at an oar or the rudder of a boat.

Form

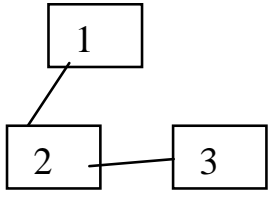

Main Idea hateful, bad-smelling deadly sharks

b Sentence of It was these sharks that would cut the turtles' legs 


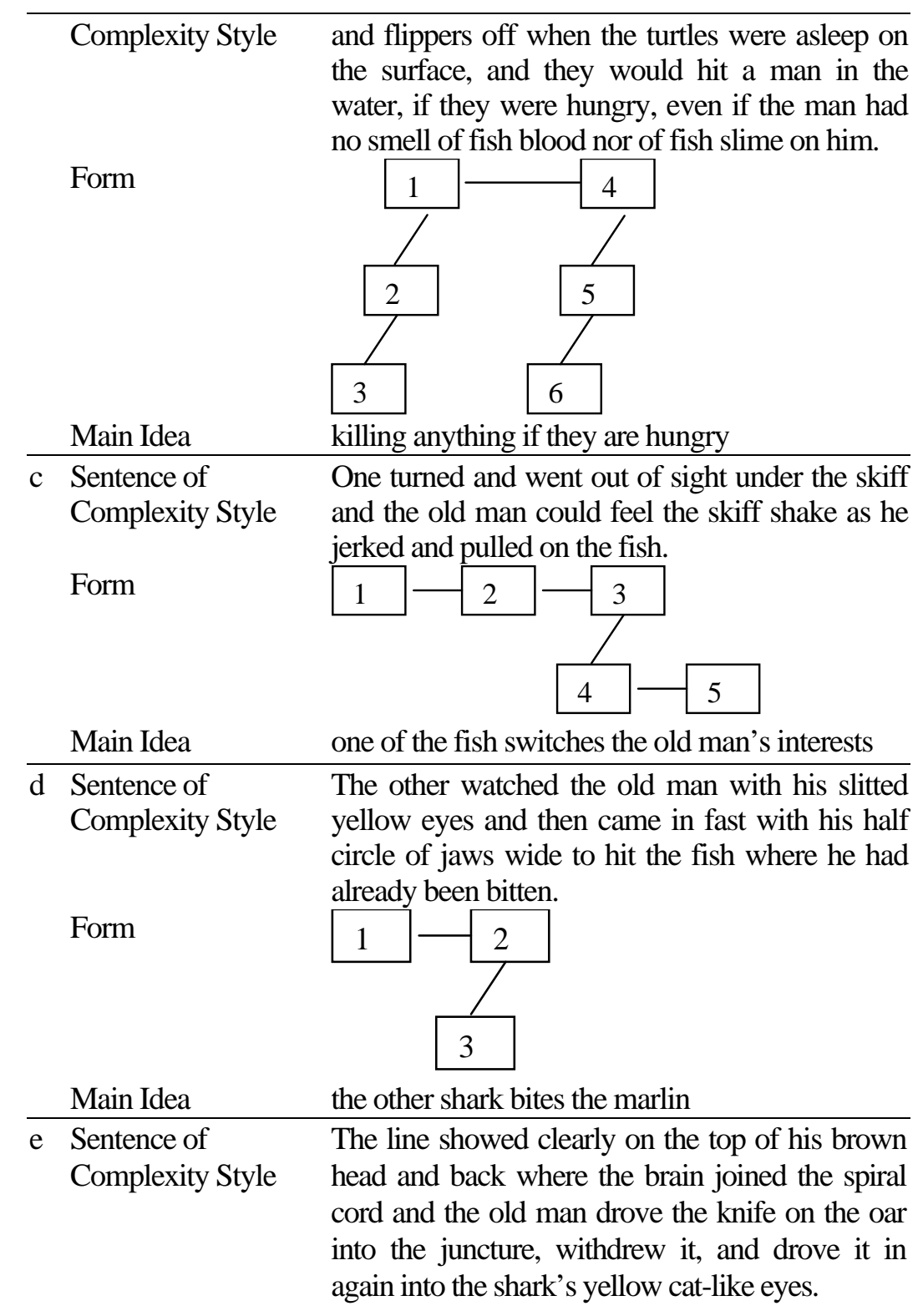




Form
Main Idea
Contence of
Complexity Style
Form
the old man hit him squarely in the centre of his
flat-topped head as his nose came out of water
and lay against the fish.

The eight sentences above show the battle between the old man and the deadly sharks. Hemingway's use of complexity style gives great details 
of the battle so that the readers are able to imagine the event clearly and this, in effect, builds the readers' suspense.

\section{CONCLUSION}

Having analysed the internal deviation in Hemingway's The Old Man and the Sea and how it is used to support the suspense and foreshadowing, I think Hemingway has succeeded in making the story more interesting and enjoyable as well as less monotonous because the readers will always be kept in suspense and curiosity to know how the story is developed.

As for the use of the writing style, Hemingway has deviated from his own principle, and it is intentionally done to support the elements of plot in the novel. This is not something simple for an author to do for it needs high skill and creativity. However, this skill and creativity of the author has to be responded with the same skill and creativity of the readers. Otherwise, there will be no appreciation for the author's extraordinary writing style, not to mention that the readers will not be able to get the author's implicit meanings, which, in my opinion, is more important than getting the explicit meanings.

\section{REFERENCES}

Crystal, D. (1987). The Cambridge encyclopedia of language. London: Cambridge University Press.

Hemingway, E. (1952). The old man and the sea. London and Southampton: The Camelot Press.

High, P. B. (1986). An outline of American literature. New York: Longman.

Jackson, H. (1980). Analyzing English: An introduction to descriptive linguistics. Oxford: Pergamon Press.

Leech, G. N., \& Short, M. H. (1994). Style in fiction: A linguistic introduction to English fictional prose. Essex: Longman.

Wales, K. (1994). A dictionary of stylistics. Essex: Longman Group UK. 